Gadjah Mada International Journal of Business

September 1999, Vol. 1, No. 2, pp. 133-143

\title{
THE HOUR TO UNDERSTAND AND FAMILIARIZE WITH CULTURAL SETTINGS FOR MARKETING IN THE THIRD MILLENNIUM
}

\section{Wachinga Gikonyo Simon}

Much of the literature about culture is related to the crafting of strategic organizational culture. This is viewed as a lee-way to attainment of competitive advantage in the field of quality production at the expense of the impact that culture could have in not only influencing the consumer behavior but more importantly in designing and planning marketing strategies in the era of globalization.

This paper, therefore, undertakes to examine various cultural settings and along which their implications will be dealt with in detail in order to display the interactive relationship that prevails between culture and its attributes, and consumer behavior on one hand, and the implication of their interaction to strategize for global market opportunities by avoiding culture-marketing clash on the other hand. This paper will not provide a set of proposed strategies that should be adopted by a global marketer in order to avoid the cultural dilemmas. At best it will attempt to pin-point those areas of cultural settings that calls for intensive if not extensive understanding and familiarizing at the same note in this critical era of market competition as we head for the yet to be defined the third millennium.

Keywords: consumer behavior; cultural settings; global market opportunities; marketing strategies; third millennium 


\section{Introduction}

Different authorities have endeavored to define the concept of culture differently but they seem to agree on some certain aspects as can be inferred from the following postulations. Culture includes both conscious and unconscious values, attitudes and symbols which shape human behavior and are transmitted from one generation to another (Terpstra 1978). Hall (1960) stated that:

"Culture is man's medium; there is not one aspect of human life that is not touched and altered by culture. This means personalities, how people express themselves (including shows of emotion) the way they think, how they move, how problems are solved, how their cities are planned and laid out, how transportation systems function and are organized, as well as how economic and government systems are put together and function."

Using the two foregoing views of what culture constitutes we can conclude that culture comprises of the complex whole of tangible items, intangible concepts and social behaviors that define a group of people or a way of life.

Culture is double-faceted. First, there is material culture, which comprises of all the tangible things that man makes, uses, and gives value to such as Rosary beads for prayers. Second, the nonmaterial culture that comprises of values, beliefs and rules by which a society directs people's interaction such as the use of nonverbal communication. Culture has values, that is, the shared standards of what is acceptable and unacceptable, desired and undesired, good and bad, expressed by norms. Its boundaries are norms i.e. the simple rules for behavior that are established by cultures, which specify or prohibits cer- tain behaviors. Malaysia, like Maldives, which is dominantly Muslems, has strict censorship rules with little tolerance for movie scenes depicting nudity, sex, foul language, graphic violence, and sensitive religious themes. As an example, the rejection of the Hollywood animated musical program "The Prince of Egypt" was interpreted offensively due to the way Moses is portrayed in the film. Here, there is no debate for good or bad-but it is the cultural sensitivity which ought to be clearly understood before one launches for a market and/or, marketing strategy adoption.

Alongside culture there are aspects such as life-styles and social classes. Lifestyle refers to the patterns of living that reflects how people allocate their time and money while a social class refers to a way of categorizing people on the basis of their values, attitudes, life-styles, and behavior.

In short, culture should be understood in this case to comprise of the psychographics. By psychographics I mean, all the psychological variables that combine to shape our inner-self including activities, interests, opinions, needs, values, attitudes, personality traits, decision processes, and most importantly buying behaviors.

From this definition we can clearly infer that every consumer is a product of culture and society, social class and family. Much attention has been given to the role of culture on consumer behavior. Yet, despite the recognition of such factors, little attention has been paid to examining their implications for the development of marketing strategies especially as regards towards capturing future global market opportunities in the face of globalization and competition. The globalization trend suggests the potential for market segmentation on a cross-national basis. Therefore, 
Simon—TheHourtoUnderstandandFamiliarize withCulturalSettingsforMarketing...

this calls for further anatomy of the cultural influences in order to understand how to achieve global market development, product positioning and promotion, communication and distribution.

As mentioned earlier, this paper will examine how some of these cultural settings (factors) can affect consumer behavior, and to illustrate thereby the need to consider cultural aspects in handling global marketing strategies for the existing opportunities. Some key elements of the cultural setting are outlined and the decision areas and examples of situations in which these play an important role are discussed. Last, the advantages and insights to be gained from looking at cultural factors as relates to global marketing are described.

\section{Cultural Setting and Consumer Behavior}

Cultural differences comprise probably one of the most important barriers to enter into international market as posited by Karakaya and Stahl (1991). Culture affects all areas of marketing ranging from product design acceptance, the role of family members in the purchasing process, communication methods, relations with distributors, and physical distributions. Material culture affects not only the demand, quality, and type of the products demanded, and their functional features, but also the production and the distribution (Cateora 1993). As such consumers operate within their cultural environment, they evaluate and respond to marketing offerings in different ways.

At present, there is no consistent theoretical framework on the impact of cultural forces on behavior in general. Even the theoretical framework provided by the social science does not provide adequate and vivid direction for investigating of cultural influences in relation to the consumer behavior, and especially so in the face of cross - cultural diversity. However, one can identify some themes, which are specifically relevant to the development of global marketing opportunities.

Pivot to any culture or society is a set of values, shared by its members, which determine what is socially acceptable behavior. For example Engel et al. (1973) summed it up as follows:

"The Saudi Arabian and his neighboring Gulf Arabs are essentially one and the same people; they do not like to negotiate by paper. They want to feel out ... to talk, to assess, to bargain... and...the following characteristics are some that Arabs value highly: quiet, secure strength (neitheraggressiveness nor waffling); patience (no time pressure); and friendship (commitment not competitiveness)..."

A culture's core values define how products are seen negatively or positively and define how market relationships are set up (Bovee and Thill 1992).

In the light of this, the race relations are also seen to vary from country to country. For instance, in Indonesia we can still see television commercials for Sony Television with "clear quality" and "29 inch big screen" with its blatantly racist African caricatures. Cultural values of a society are not abstract notions since they find their expression in the products and service that are demanded and the acceptance of which may be very dependent on cultural norms (Chisnal 1986).

This means that cultural inhibitions may frustrate the introduction or diffusion of a new product. This is especially so because even relatively fundamental needs such as food and clothing have become complex and sophisticated in modern 
times. For instance, the most affluent consumers have built a high edifice of needs (psychogenics).

The rules regarding the exchange of gifts are closely governed by local conventions. For example, during a traditional wedding party among the Kikuyu tribe of Central Kenya, a couple would expect to receive tangible products of value as gifts, unlike among the Americans where a congratulation card suffices the occasion.

Although the relationship between advertisement and consumer rituals has not been explored, we find that the former can influence consumption during such ritual ceremonies as hunting. From the former Sony TV commercial, we find that there are four players namely; the Cheetah chasing the Antelope and the Maasai hunters armed with spears and shields which I assume must be reflecting the natural game hunting spree by the Kenyan tribe beside the marketer's role objective for its choice; and the " 29 inch big screen" reflecting the victim of the spree, the antelope, which is finally caught by the hunters but not the chaser. Whatever the meaning of the commercial, the point is that advertisement employs ritual symbolism to create messages about a product and service designed for use during such occasions. It is therefore vital for a marketer to be acquainted with the cultural rituals before undertaking any promotional strategy for his product and above all avoid conflicts arising thereof.

The network of social organizations generates different customs regarding male-female social interaction (Pride and Ferrell 1985). For example, sales promotion based on the couple's togetherness and of material life could backfire in most African Anglophone countries where husbands and wives often lead separate lives. This is not just because of dual career couples' problems, it has cultural roots too. The theme may do well in Indonesia especially among the Javanese community. Likewise, adoption of gender-oriented promotion such as women photographs may meet stiff opposition in places like Saudi Arabia, though most writers associate with its religious ethics.

Each country has its own folkways, norms, and taboos, and these in turn determines the buying habits and business dealing within a region or on a micro-level of a community (Russ and Kirkpatrick 1982; Kotler 1988). At the end, this will be translated into cultural differences among nations. These cultural differences are apparent not only among the consumers in different countries, but among the business executives representing the parent industry abroad in its subsidiaries, too.

This can further be illustrated by the ways in which different communities attach some certain numbers or products. For instance, women in Tanzania will not feed their children with eggs for fear of making them bald or impotent for the worse. Likewise, most African communities associate red color with danger. As such red clothes are avoided in order not to attract the wrath of lightning on a rainy day. This is the case in the Lake Victoria Basin and the Central Highland of Kenya in the Kikuyu Plateau.

Culture transmits systems of communication among the people about edibility and toxicity and replete of a product. As such culture defines the desired attributes of a product, it also affects the mapping of sales territories (distribution) the theme used or color in product promotion, the pricing. People choose products that communicate their role and status (Kotler and Armstrong 1996). For example, a bicycle tire bearing a brand name 'made in India' is regarded as of low quality in 
Simon—TheHourtoUnderstandandFamiliarizewithCulturalSettingsforMarketing...

Kenya, as opposed to those carrying the brand name 'made in China'. All of this resulted from the weak national image Kenyans have towards products from India. Furthermore, clothes labelled "made in Indonesia" sells faster because the name has textile longevity quality meaning from time in memory.

Mannerism and ethics are culturalbased. In some countries for example in South Korea, saleswomen like to usher in a customer into the shops while placing their hands on the latter's shoulders as a sign of welcome, whereas in Japan it is unlikely because it is not socially condonable.

Racial and ethnic identities affect both self-image and consumer behavior. Due to difficulties involved in separating the two, we find that even in given regions of a country a particular race or ethnic group is subdivided further down into small subcultures. Thus, members do not identify themselves with the broader classification (William 1992). Therefore, an advertisement aimed for the same group may not express its message. The Hispanic community of America is a good example. On the same racial tone, one cannot fail to appreciate the fact that racial sentiments have done much to explain about the consumption of certain products or service. If one could make a flashback of the notorious Dred Scott decision of 1857 by the Missouri Supreme Court which declared the entire class of human beings, the people of African descent, as outside boundaries national community and the constitutional protection one may find it as a crucial factor that has contributed to high consumption of music opposed to racial prejudice among the Afro-Americans. This, of course has been far revised in the recent past, though not overturned the ruling entirely because racial sentiments still hov- ers. Where such racial sentiments prevails, there is bound to occur such racial and even ethnic identification, in order to show that they are not handicapped and are useful. Here, the issue is not to preach of the racial feelings but to show the importance of understanding the history behind a cultural phenomenon in a given target market before one designs a market strategy especially on a transnational platform.

Moreover, etiquette and politeness, and attitude as regards one's body and time could tremendously affect the behavior patterns (Russ and Kirkpatrick 1982). For instance the Asian time is spent "honoring" especially by letting the ranking person lead the conversation uninterrupted. The imperative for selling in Asia is to be on the wavelength of the cultural values of the country one is dealing with. For instance, among Indonesian business people there is a term (jam karet) roughly translated as 'rubber time' (Bovee and Thill 1992). All it implies is that time is elastic and unstructured unlike in the Western cultures. This does not imply that there are no cross-cultural markets. All it requires is adjustment and doing a lot of homework to thoroughly understand the market. Likewise, Asians seldom respond to an abrupt and direct approach, and as for Arabs, they would rather lose a deal rather than do business without harmony. Their way of refusing a deal is manifested in many forms since they regard definite refusal as counterproductive and insulting.

Another case in point is kissing of another one's wife. Among the Americans, kissing of another's wife is usual whereas among most African communities it may culminate into divorce. Some parts are held sacred in some communities, and not in others. For instance, patting of another person's head among the 
Americans is common practice whereas for the Orient communities it is held sacred.

Religion is a mainspring of culture as it influences consumption behavior and attitudes towards time which are fundamental to understanding consumer and buyer behavior (Terpstra 1978). Different religions hold different views about consumption of various products. For instance, Hindu does not support eating of cattle because it is regarded with sacredness.

Even for services such as banking, we find them guided by religious teachings upheld in a particular society. For example, banking in United Emirates and Pakistan today operates not with the aim of making interest (Riba). The outgoing principle follows the Holy Koran teaching which outlaws usury or excessive interest on any banked money. However, it supports partnerships, joint ventures, and profit-sharing thus dispelling any form of business that leads to speculation on money invested in the bank for a fixed interest rate earning. Related to this form of banking, one finds that such business undertaking should be far removed from production of pork related products or alcohol (Powel 1997). As a result, it behooves any marketer worth his salt to go full blast into investigating cultural settings that suit a society in which he is ready to face in order to avoid uncalled for dramatic failures resulting from unwarranted ignorance.

All these aspects of culture are transmitted to a consumer (individual) through the communication system and language of the society or subcultural group. The inherent values, social institutional arrangements and behavior conventions conveyed through communication and language leads to foundation of characteristic daily routines and rhythms. In Indonesia for example, billboards and other road- side advertisements must use only the diverse cultural segments of the society (Kotler et al. 1996). This is what will precipitate to consumption and purchasing activities. So, understanding these temporal cultural settings are vital for a global marketer. Furthermore, the values, behavior and patterns of a society are dynamic in the face of globalization, industrialization, urbanization, technology, and social mobility that have culminated into introduction of new cultural patterns and values. This does not, however, imply that old cultures have been thrown overboard but they should be learnt as one because not all aspects are influenced by all the factors named in this article. As such it ought to be taken as a microcosm on which to build the fundamental basis for interfacing culture and global market strategy to capture the existing opportunities in a given cultural setting.

\section{Implication of Cultural Setting to the Global Marketing Opportunities}

Cultural factors (settings) as can be inferred from the foregoing analysis posts such a pervasive influence not only designing the marketing strategies but more so the planning of the marketing mix. That is, cultural settings can provide opportunities or weaknesses.

Understanding of cultural practices can be useful in assessing the kind of, nature of, and combination of strategies to adopt in, not only within a country, but even down to the regions where we have various subcultural groupings. Asians, for example, prefer interdependence (e.g. Indonesians call it-gotong royong), harmony and "honoring". Hence, it would require a foreign marketer to observe; respect and deference, affirmative, and 
Simon—TheHourtoUnderstandandFamiliarize withCulturalSettingsforMarketing...

obliqueness in order to communicate with the customer in such a cultural setting.

An appreciation of cross-cultural differences in values is essential to understand the needs and tastes of customers or clients around the world. It is also important when the customer enters one's own culture. For example, some working women no longer prepare food at home and would prefer to buy ready-made dehydrated and frozen food. As such, marketers could adapt to promotion of such products with the aim of capturing the niches provided by such working socialclass market segment. This, they could achieve by using the market research and available census data in that country, or, a region to assist in identifying the structure of social classes.

Likewise, marketers must be aware of diverse subcultures by examining them individually and on their own terms in order to avoid damaging conflict with the broadly accepted cultural standards. For example, the sensitive issues in the society such as abortion and safe sex apparatus could be promoted with care and tastefully appeal to a given cultural setting. This could only be achieved by correctly identifying the factors that is more predictive for a particular product.

The marketers must check out the way foreign consumers think about and use certain products before planning the marketing program. Illustration of this could be drawn from the earlier mentioned case of the Tanzanian women and their attitude towards the feeding of their babies with eggs and Central Kenya community's attitude towards the association they hold towards consumption of red clothes.

Differences in the cultural environment of foreign countries may be misunderstood and/or, not even recognized because of the tendency for marketing ma- nagers to use their own cultural values as terms of and a frame of reference. This is likely bring problems for such a blindly guided global marketer. Thus, the cultural framework of consumer motives and behavior is an integral part of the understanding of the foreign consumer.

Cultural values and attitudes towards the material culture, social organizations, the supernatural aesthetics, politeness and etiquette and language, ought to be analyzed for their possible influence on each of the elements in the firm's marketing program.

Since culture seems to govern our eating habits and clothing, it is important that the global marketer appreciate its impact on product development, promotion, distribution and pricing of the same products in different markets in order for them to capture the prevailing market opportunities across a vast cultural diversity.

Similarly, awareness of the ways pictorial conventions are interpreted can be critical. Again, let us revisit the Saudi Arabian case where the using of women photographs as a case model for advertisement is prohibited. It is only once when the marketer has a clear understanding of the Saudi's culture will he be in a position to interpret the reaction of consumers to alternative marketing strategies (Loudon and Della Bitta 1979) and will change accordingly.

When products are introduced into one nation from another, the acceptance is far more likely if there are similarities between the two cultures. For instance, the clearly- drawn cultural line established in Europe has encouraged stereotypes against products from other countries. All this will result from factors associated with race and ethnicity. So, the international marketer ought to choose (be sensitive) to cultural differences, especially when it 
comes to media choices with an effort to achieve effective communication. This should encompass media rescheduling in order to have a vast reach.

The conotation of words, numbers, and symbols requires careful attention too. For example, a raised thumb in the Western World may be taken as a sign of approval just as nodding the head is among the majority of the African Countries. To the Arabs it may be taken as an insult equivalent to asking someone to sit on that finger if ever one dared. This and other body or formal words and symbols may present great barriers to the promotion of a product for different cultural groups. It behaves the companies to send their cadres overseas to learn about different and general acceptable cultural traits and moreover, the languages, in order to prepare adequately.

A global marketer should therefore be thoroughly equipped with communication policy and courtesy because it is where cultural impact is keenly felt. It determines the appropriateness of promotional themes in the face of cultural acceptance and interpretation of the message. Inadequate information about foreign cultures is a common cause of error (Evans and Berman 1990). The global marketer must be certain, therefore, that the sales personnel have an understanding of the influence of culture on communication. Unless the latter understands the cross-cultural communication overtones the sales process could end up in doom. This further calls for the understanding of the nuances in both the spoken as well as the silent language such as idioms and body expressions. Moreover, it behooves a marketer to develop trust upon his clients by creating cordial relationship.

Perhaps an even more nagging situation arises during the product positioning.
It is a great prerequisite for a global marketer to understand the significance and social symbolism of products in different cultural settings to enhance the designing of positioning strategies and other related decisions such as pricing or packaging. Even when a product is too different to market because of cultural incompatibility, astute positioning strategy may be required. For example, a marketer may choose to position the product as an exclusive and luxurious one to depict it as one used among a distinguished social class from an esteemed country or a region. Or, depict the product as compatible with a distinguished life-style.

Choice of distribution channels in global markets can be restricted by cultural conventions. For instance, a marketer who intends to use saleswomen in a cultural setting must thoroughly understand the social conventions prevailing in a given cultural group and even in a subculture. Among some African communities, home sales by women are regarded suspiciously as an intrusion of the family privacy and this greatly affects the effectiveness of door-to-door sales. Worse still, such saleswomen are socially regarded as social misfits who might be coming from broken marriages or as "sexual loose" (prostitutes). At least, such occurrences are limited to ethnic background and tribal cultural beliefs and sentiments. To a global marketer, she needs to be acquainted with cultural groupings to help her in segmenting the market rather than using the social, political or geographical borders.

In any given country (market), there are ethnic or racial minority who similarly have a culture that influences their consumption behavior. Hispanic consumers retain cultural habits, attitudes, interests, and behaviors even though they are proud to be Americans. Therefore, to success- 
Simon—TheHourtoUnderstandandFamiliarize withCulturalSettingsforMarketing...

fully reach an ethnic consumer, marketers need to consider a new picture of America. This implies choosing strategies that touch the mosaic of America. This is one factor that poses constraints to international marketing. In itself, it is a resourceful opportunity for market.

Recent demographic changes indicate the increasing importance of ethnic minority consumer in America (Cui 1997). For instance, in the foregoing case, a global marketer could adapt such strategy like ethnic marketing in order to tap factors such as ethnic identification and acculturation. For this kind of endeavor, one needs more than product marketing. That is, passion and perseverance. This could be achieved by identifying with that particular people by learning their language for both advertisement and distribution of product. Ethnic marketing is not for the faint-hearted. What is important is reaching the right people. This will assist in creating an inclusive market rather than an exclusive one. Knowing that ethnic or racial consumers have different perspectives that affect their emotions is critical to being an effective ethnic marketer.

Today, there is a trend towards cultural shift that necessitates the global marketer to be vigilant. That is, the changing gender roles, the emergence of variation of families where there is single parenthood, families without children, men or women living single in small apartments, and more importantly the increase of leisure time especially in the developed countries. Marketers oriented to family-oriented products have to fashion new products suitable for each family variation and develop new selling appeals for existing products to represent the values, attitudes, and life-styles. The rise in gender roles due to the rise in the number of working women in the society requires marketers to adjust their marketing research, and product design promotion to suit gender choice.

From the environmental experience there seem to be cropping up another subculture especially so emanating from the youngsters age-sets .This group has been breathing and forms a tangible, as well as a formidable, market catch. This is manifested in various forms ranging from small groupings to isolate, but whereby in both categories, their cultural orientation are similar if not a mirror-reflection. The culture has evolved bearing diverse names as the members' backgrounds differ. In Kenya where I come from, that culture is referred to as 'US GUYS'. I believe that this has mushroomed and deeply ingrained in almost any community the world over. In Indonesia, though I am not conversant with the name adopted for this culture, its manifestation comes inform of too much adoration for noisy hooting motorbikes or to the extreme vibrating exhaust piped autos. Their Kenyan counterparts likes shaving 'punks' (a form of hairstyle cut), are associated with wearing baggy-jeans trousers or miniskirt among ladies and listening to loud music by mounting earphones on their heads wherever they are found. Here, I am not out to discuss behavior that is often associated with adolescent stage but about a crucial group comprising of both working and nonworking people who could be harnessed for market only once a marketer has carried out enough study to understand and familiarize with that form of a cultural setting wherever it may be. The feasibility as well as viability in attempting to exploit this market is greatly justified by their high propensity to consume for any product or service that meet their expectation. As such, studying such like cultural setting is a worthwhile investment not only at a local level but on a global alike. 
Gadjah MadaInternationalJournal ofBusiness, September1999, Vol.1,No. 2

\section{Conclusion}

Examination of and thoroughly understanding of a cultural environment in a market location is a key and vital tool to a global marketer who intends to tap the scarce competition market opportunities. The reason for this is because it provides insights and pitfalls especially for global market development and segmentation strategies. The cultural setting provides hints on how to carry out the distribution, positioning, pricing and communication decisions.

Understanding the culture and its dynamic changes will assist in not only transferring the product across - cultures but more so, to compare the similarity in needs and problems with the aim of predicting the future trends.
Worthy of attention is the fact that the global marketers are assisted in crafting effective strategies for different country cultures and evaluate them alongside those found in another cultural or subcultural setting. A global marketer must recognize the cultural influence and must be prepared to either respond or to change especially in the food and service industry. The management should undertake detailed research regarding the effect of culture not only on consumer behavior but also on marketing strategies and their design. With such market cultural intelligence data in place, the global marketer will be assured of the correct definition of the third millennium marketing trends.

\section{References}

Bovee, C. C., and J. R. Thill. 1992. Marketing, International Edition, Toronto: McGrawHill Inc

Cateora, P. R. 1993. International Marketing. $8^{\text {th }}$ Ed. Chicago: Irwin Co.

Chisnal, P. R. 1986. Marketing Research. $3^{\text {rd }}$ Ed. London: McGraw-Hill Inc.

Cui, G. 1997. Marketing strategies in a multi-ethnic environment. Journal of Marketing Theory and Practice (5) 1: 122-134.

Engel, J. F., T. D. Kollat, and D. B. Rogger. 1973 Consumer Behaviour. $1^{\text {st }}$ Ed. New York: Holt Rinehert and Winston Co.

Evans, J. R., and B. Berman. 1990. Marketing, ${ }^{\text {th }}$ Ed. , N.Y.: Macmillan Co.

Hall, E. T. 1960. The silent language of overseas business. Harvard's Business Review (May-June): 87-97.

Karakaya, F., and M. J. Stahl. 1991. Entry Barriers and Market Entry Decisions, N.Y.: Quorum Books Ltd.

Kotler, P. 1988. Marketing Management, Analysis, Planning, and Control. $6^{\text {th }}$ Ed. Englewood Cliffs, N. J,: Prentice Hall Inc. 
Simon—TheHourtoUnderstandandFamiliarizewithCulturalSettingsforMarketing...

Kotler, P., H. S. Ang, M. S. Leong, and T. C. Tan. 1996.Marketing Management: An Asian perspective. N.Y.: Simon and Schuster Ltd.

Kotler, P., and G. Armstrong. 1996. Principles of Marketing. $7^{\text {th }}$ Ed, N.Y.: Prentice Hall.

Loudon, L. D., and J. A. Della Bitta. 1979. Consumer Behaviour and Applications, N.Y.: McGraw-Hill Inc.

Powel, A. E. 1997. Islamic banking draws foreigners. Jakarta Post (8): Dec., 7.

Pride, W. M., and O. C. Ferrell. 1985. Marketing: Basic Concepts and Decisions. $4^{\text {th }}$ Ed. Boston: Houghton Mifflin Co.

Russ, F. A., and C. A. Kirkpatrick. 1982. Marketing. Boston: Little Brown and Co.

Terpstra, V. 1978. The Cultural Environment of International Business. N.Y.: SouthWestern Co.

William, W. 1992. Advertising - Principle and Practice. New Jersey: Englewood Co. 